\title{
La memoria de los verdugos
}

\author{
Remember | Atom Egoyan | 2015 \\ Eduardo Laso* \\ Universidad de Buenos Aires
}

Recibido: 11 de junio 2016; aprobado: 15 de septiembre 2016

\begin{abstract}
Resumen
Lacan sostiene que de nuestra posición como sujetos somos siempre responsables. Y que un acto produce un sujeto nuevo. Un acto criminal también produce un nuevo sujeto. Luego de dicho acto, la pregunta es qué posición asumirá el sujeto que ha sido producido como criminal. Remember de Atom Egoyan nos confronta con este problema. El film trata sobre la justicia y la responsabilidad, el problema de la memoria por actos imperdonables y las decisiones sobre el pasado criminal.
\end{abstract}

Palabras Clave: Culpa | Genocidio | Responsabilidad | Memoria

The memory of the murderers

\begin{abstract} acts, and the decisions about criminal past.

Keywords: Guilt | Genocide | Responsability | Memory
\end{abstract}

Lacan sustains that we are always responsible for our position as subjects. Otherwise, that act produces a new subject. A criminal act also produces a new subject. After a criminal act, the question is what position will asume the subject that has been produced by that act. Produced as a criminal. Atom Egoyan's Remember confronts us with that problem. The film is about justice and responsability, the problem of the memory for unforgivable insignificantes de nuestro pasado persisten en nuestro recuerdo, y caen en el olvido acontecimientos que por su significatividad marcaron nuestra vida. Todo recuerdo es en última instancia "encubridor" y está atravesado por motivaciones inconscientes que operan sobre las huellas mnémicas, determinando tanto lo que se olvida y lo que se recuerda, como el modo en que nuestra memoria acude a la consciencia luego de ser afectados los hechos pasados por distorsiones, transacciones e infidelidades. Olvido y recuerdo están inconscientemente motivados y tienen un destinatario: se recuerda para alguien que ocupe el lugar del Otro. De ahí que en los recuerdos el sujeto -y también una sociedad- al mismo tiempo se reconoce y se desconoce.

La memoria -personal y social- está inscripta en huellas que testimonian del pasado. Y es la historia la encargada de volver esas huellas un discurso. Cómo se leen las huellas hace al campo de las diversas interpretaciones del sentido del pasado, las que no

* lasale_2000@yahoo.com 
escapan a la trama de los deseos, ideales y fantasmas inconscientes -sean del sujeto o de una comunidad-. El rehusamiento de la lectura de las huellas, en cambio, es ya un esfuerzo de rechazo de lo acontecido. De forcluir lo ocurrido.

Remember de Atom Egoyan, nos confronta con el problema de la memoria y el recuerdo no de las víctimas de crímenes de lesa humanidad -o de los descendientes de ellas, tema que trató en el film Ararat, a propósito del genocidio armenio- sino de los victimarios. Son escasos los testimonios escritos $\mathrm{u}$ orales de genocidas, si se lo compara con los de las víctimas. Y se comprende que esto sea así, dado que jurídicamente nadie puede declarar en su contra y generalmente el criminal no se siente motivado a hacerlo. Las pocas veces que eso sucede, sea por remordimiento o porque fue forzado a hacerlo en el escenario de un tribunal y no puede ocultar su responsabilidad (como ocurrió con muchos jerarcas nazis), nos encontramos con un tipo de discurso generalmente exculpatorio como modo de defenderse del juicio condenatorio que proviene de los semejantes, o incluso de él mismo. Maneras de eludir la responsabilidad jurídica y moral, dejando fuera de consideración la cuestión del deseo que condujo al sujeto a suscribir o a apoyar determinados actos criminales contra un grupo humano. El argumento de la obediencia a la autoridad ("otro hubiera hecho lo mismo en mi lugar", "obedecí órdenes", “cumplí con mi deber"), la disociación temporal entre aquel que fue en el pasado y el yo actual ("en ese momento no sabía lo que después supe", "fui engañado por el partido", "por esa época era muy joven”), la denegación (“yo no hice nada”), la proyección ("ellos amenazaban nuestra forma de vida y hubo que defenderse", "somos juzgados como criminales por haber perdido la guerra; de lo contrario seríamos héroes y estaríamos juzgando nosotros"), son las típicas estrategias que buscan legitimar al sujeto frente al Otro y ante sí mismo.

Cuando un genocida debe comparecer por sus delitos en un juicio, suele combinar la amnesia selectiva con la auto indulgencia y la exculpación: no recuerda lo que no le conviene, niega el derecho de otros a que lo juzguen, proyecta la culpa sobre las víctimas -que pasan a ser victimarios-, niega que haya cometido delitos, y exhibe toda una parafernalia de justificaciones de las que está seguro que la Historia y Dios lo absolverán.

Que un victimario de genocidio se rehúse a recordar ante un tribunal no significa que no haya memoria del crimen cometido, tanto subjetiva como objetiva. Las huellas que deja su acto constituyen una memoria, más allá de la mala voluntad de recordar: desde las pruebas de ADN, las huellas dactilares, las fotos o los videos, hasta los testigos y los sobrevivientes operan como marcas dispuestas a ser leídas. Es que, como planteaba Freud en Moisés y la religión monoteísta, el problema de un crimen no es tanto cometerlo, como borrar sus huellas. No hay crimen sin huella, aunque haya en el perpetrador la voluntad de borrarla. Éste querría la borradura de toda huella del acto criminal, como pretendía el Reichführer de las SS Heinrich Himmler en su célebre discurso de Posem, el 4 de octubre de 1943 ante soldados y generales a propósito de la Shoah: "esa es una página de gloria de nuestra historia que nunca se ha escrito y que nunca se escribirá". Una amnesia personal y colectiva, un Alzheimer social sobre los crímenes perpetrados. Que haya un crimen sin huella. Un crimen perfecto. Semejante olvido equivale a una segunda muerte para las víctimas: la denegación misma de que hayan existido y que se las haya asesinado. Se intentó en la Argentina con la figura del "desaparecido". Y Turquía sigue insistiendo 100 años después con que el genocidio armenio no aconteció. Se trata de borrar la huella misma del crimen y la inscripción simbólica del muerto en la memoria de los vivos. De ahí que el olvido del crimen constituya un crimen de olvido, y que sea responsabilidad de los Estados y de los pueblos una política de la memoria que no incurra en una denegación de la existencia de las víctimas, según el deseo de los victimarios.

Dada la enormidad de los crímenes cometidos por un genocida-Hannah Arendt decía que eran tan graves que excedían toda medida jurídica de castigo: no había modo de pensar en un castigo proporcional al crimen cometido, porque su exceso mismo lo volvía inconmensurable al pensamiento racional ${ }^{1}$ - la alternativa a las estrategias exculpatorias sería una asunción de las responsabilidades por los actos cometidos, lo que implica para el sujeto que el exceso del crimen retorne en forma de autoacusaciones, de algo imperdonable que sólo puede saldarse con el suicidio.

La estrategia intermedia consiste en una escisión del Yo: reconocer los crímenes cometidos y al mismo tiempo plantearlos como cometidos por otro, "aquel que fui y ya no soy”. La división del yo es una estrategia común entre quienes participan de actos criminales requeridos por el Estado en determinado momento histórico y luego, cuando las circunstancias históricas cambian, dichos actos pasan a ser condenados y juzgados. 
Néstor Braunstein recoge varios ejemplos de esta Spaltung del Yo. ${ }^{2}$ Tomemos el caso de Günter Grass, el célebre escritor alemán que luego de 60 años confiesa en sus memorias que fue miembro de las Juventudes Hitlerianas, provocando un escándalo internacional, dado que durante décadas el autor de El tambor de hojalata fue un agudo crítico del nazismo y de las complicidades de los alemanes con el régimen genocida de Hitler. Lo que Braunstein destaca de la escritura confesional que constituye Pelando la cebolla, ${ }^{3}$ es el modo en el que el autor pasa del empleo de la primera persona del singular a la tercera, como si hablase de otra persona, en aquellos pasajes en que habla de su vinculación con el nazismo. Por ejemplo: "Durante los últimos años de la Ciudad Libre de Danzig, el chico que llevaba mi nombre se adhirió voluntariamente a la Juventud Popular, una organización que acabó por ser la Juventud Hitleriana. ... Como fueron tantos los que guardaron silencio, se siente una fuerte tentación de relegar a segundo plano nuestro propio silencio o de compensarlo invocando la culpabilidad colectiva o de hablar sólo en abstracto de uno mismo en tercera persona: "Él era, vio, tuvo, guardó silencio...”.

Lacan planteaba que de nuestra posición de sujetos somos siempre responsables. Y respecto del acto, que produce un sujeto nuevo. De esto se sigue que quien lleva a cabo un acto criminal, carga con las consecuencias de su acto. Acto que lo produce como sujeto. En cierto sentido, es correcto el planteo del genocida respecto de su escisión, sólo que es incorrecto el punto en el que lo sitúa: no entre la comisión de crímenes y su juzgamiento (lo cual le resulta conveniente), sino entre el antes y después de cometer el crimen que lo produjo como criminal. Hay un antes y un después del acto, y todo el asunto es la posición que asuma respecto del acto que lo ha producido como sujeto nuevo. Para el caso, producido como asesino.

\section{Otto Wallisch: nombre metonímico de la responsabilidad}

Remember es un relato sobre la justicia y la responsabilidad, presentado en la forma de una falsa historia de venganza. El director Atom Egoyan manipula al espectador, identificado a la figura del vengador, para finalmente avergonzarlo de lo que ha estado aguardando desde sus supuestas certezas morales. Si estábamos acompañando el asesinato del policía neonazi y esperábamos que el anciano sufrido de Zev Guttman encuentre a Otto Wallisch para que lo mate, súbitamente el giro final de la trama nos pone tan estuporosos como el personaje principal. Y Max Rosenbaum, el inválido compañero de Zev en el geriátrico, pasa a ser el último sobreviviente de Auschwitz que logra hacer justicia.

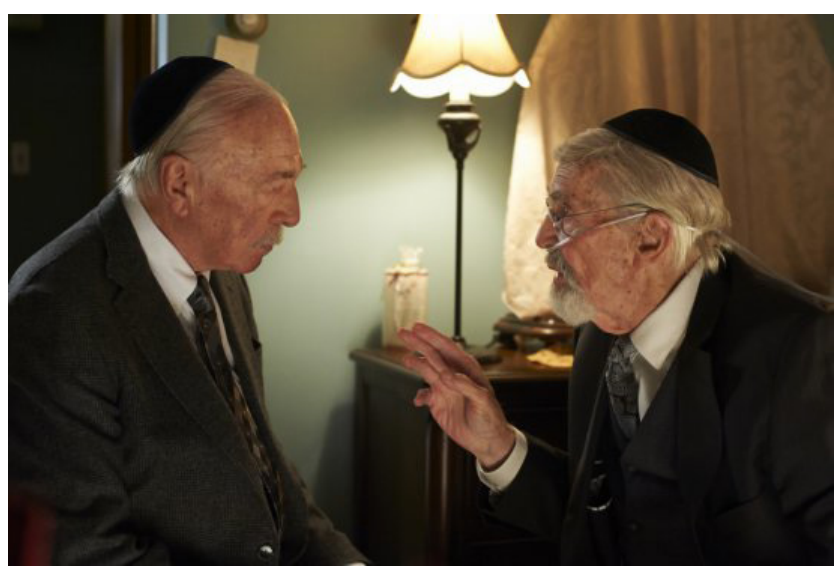

Lo que hace que Remember no sea, a pesar de las apariencias, una historia de venganza, es el personaje de Max Rosenbaum y su posición lo largo del film. El azar le ofrece la oportunidad de desquitarse de uno de los criminales que mató a su familia, cuando el amnésico Otto Wallisch es internado en su geriátrico. Pero él es un judío religioso: mal podría proponerse una vía vengativa, cuando eso es prerrogativa de Jehová. Y recuerda a Simon Wiesenthal, para quien trabajó, y su planteo ético de que todo criminal de guerra debe ir a juicio público.

Él podría haberse vengado de Otto Wallisch en el geriátrico, quien a esa altura está demente e indefenso, creyéndose un judío sobreviviente. Luego de la guerra, Wallisch construyó una nueva identidad mediante el doble mecanismo de denegar su pasado -que pasó al estatuto de inexistente- e inventarse un pasado sustituto identificándose con una víctima de la Shoah bajo el nombre de Zev Guttman. Al punto de casarse en 1946 con Ruth, una judía americana, y realizar una nueva vida armada desde la farsa de un relato en el que figura como sobreviviente del Holocausto, con los beneficios secundarios que eso reporta (reconocimiento, respeto, indemnizaciones). La mentira funcionó tan bien que se la terminó creyendo.

En determinado momento del film, en una charla entre el hijo de Zev y el director del geriátrico, se barajan varios diagnósticos para dar cuenta de las dificultades de Zev para recordar: demencia senil, trastornos neurocognitivos, trauma por duelo. ¿Cuál es la causa de las fallas 
de la memoria de Zev? ¿El Alzheimer, o la propia posición del sujeto que decidió rechazar todo rastro de lo acontecido en su pasado nazi? Los trastornos neurológicos de la memoria del personaje representan un modo radical de olvido sobredeterminado por razones denegatorias. La identificación con la víctima lo saca de todo recuerdo posible de su lugar de victimario. ${ }^{4}$

Así las cosas, ¿de qué le serviría a Max matar a alguien que ya no recuerda por qué se lo mataría? Asesinado de ese modo, moriría como la víctima inocente a la que se ha identificado para eludir la justicia y las propias responsabilidades. Que recuerde quién ha sido se vuelve decisivo para Max. Además está pendiente la ubicación de Kunibert Sturm, el compañero de Otto en el campo de concentración. Así que Max se valdrá de la conveniente amnesia de Zev, para mandarlo en la misión vengativa de buscar a Wallisch, supuestamente oculto bajo el falso nombre de Rudy Kurlander, lo que lo conducirá a Kunibert Sturm, su cómplice en Auschwitz, $y$ a que se reencuentre finalmente con su nombre propio y su ominoso pasado. Punto a partir del cual Zev deberá decidir qué hará con Wallisch y sus actos. Qué posición asumirá cuando sepa que ese asesino aborrecible que debe matar por haber cometido crímenes imperdonables es él mismo. En otras palabras, Max lo pone en el camino de una verdad -porque, como dice el mismo Zev, no se puede vivir en la mentira- y de la responsabilidad por sus actos. Así se salda por lo menos el crimen agregado, que es el crimen del olvido. Queda a cuenta de Otto Wallisch qué hará con esa verdad que lo concierne.

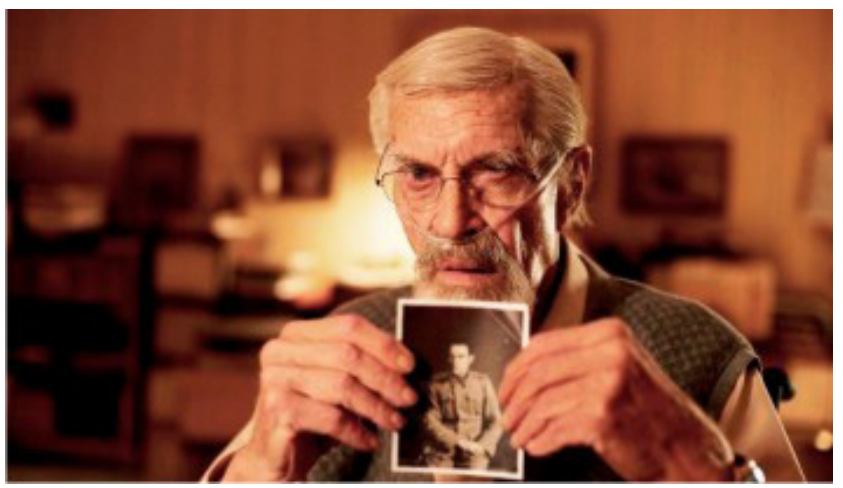

Con su palabra y una carta con instrucciones precisas, Max funciona como un Otro que suplementa la falta de memoria de Wallisch. Pero al hacerlo, se vale de la mentira que el criminal se armó, para usarla en el sentido opuesto por la que fue edificada. Max fabrica para un $\mathrm{Zev}$ inexistente una memoria que refuerza la mentira en la que ha vivido durante años: que es una víctima sobreviviente del genocidio nazi, que ha tenido a Max Rosembaum de compañero de infortunios en Auschwitz, que ambos han perdido a sus familias en el campo, que se han reencontrado al final de sus vidas en un geriátrico y que allí se han comprometido a encontrar a los responsables de las muertes de sus familias y vengarse. Max relanza un significante para Zev: Otto Wallisch. El nombre olvidado por la escisión del Yo y el Alzheimer, retorna desde el Otro que Max encarna. Este nombre propio se convertirá en la cifra enigmática de una búsqueda en torno de la identidad y la responsabilidad, bajo el guión ambiguo que Max le aporta en esa carta que-como toda carta- siempre llega a destino. Ambiguo porque el texto no le miente pero se presta a una lectura doble: "Zev, hay algunas cosas difíciles que debes saber. En primer lugar, Ruth ha fallecido. Tenia cáncer. Ella te quería y estuviste con ella, sosteniendo su mano, al final. En segundo lugar, tienes demencia. Recientemente has estado olvidando muchas cosas. Tú y yo tenemos una historia similar. Ambos somos sobrevivientes de Auschwitz. (Efectivamente, ambos lo son, sólo que en bandos opuestos) Mira tu brazo izquierdo, eras el prisionero 98814. (Aquí se vale de la mentira que el mismo Wallisch construyó y que Max utiliza) Cuando terminó la guerra, me prometí que encontraría a los hombres responsables del asesinato de nuestras familias ("nuestras" porta la ambigüedad de que no necesariamente incluye al oyente: puede estar aludiendo a la comunidad judía). Trabajando con Simón Wiesenthal, he ayudado a capturar decenas de ex nazis en todo el mundo. Hace seis meses, Dios me sonrió cuando viniste al hogar para personas mayores. (Es un acontecimiento providencial que uno de los asesinos de su familia termine en su geriátrico con un cuadro de demencia senil) De inmediato te reconocí de Auschwitz, aunque tú no me recordabas. (No miente en esto: Wallisch no recuerda a una de sus tantísimas víctimas) Somos los últimos sobrevivientes con vida de nuestro bloque de la prisión. Además de mí, eres la única persona que podría reconocer el rostro del hombre que mató a nuestras familias. (Esto es exacto, y en el film vemos una escena en la que Max le muestra una foto de Wallisch. Al final del film sabremos que estuvo confrontándolo con su propia foto como oficial nazi) Simón Wiesenthal insistía que todos los criminales de guerra debian ser sometidos a un juicio público. Sin embargo, nosotros no podemos darle a Wallisch esa oportunidad. Incluso si hubiera suficientes pruebas, él-como nosotros-, probablemente moriría antes que pudiera ser extraditado a Alemania. Hemos acordado que Otto Wallisch debe morir. (No sabemos si esto es un engaño de Max o si en algún momento efectivamente 
acordaron eso. A los efectos de la posición ética que el film pretende transmitir, entiendo que se trata de la segunda alternativa: visto desde la posición de víctima de la Shoah -o sea, visto desde el punto de vista de Zevel crimen se vuelve horroroso e imperdonable) Tú debes matarlo. Prometiste ir una vez que Ruth muriera. Me lo prometiste a mi y se lo prometiste a Ruth".

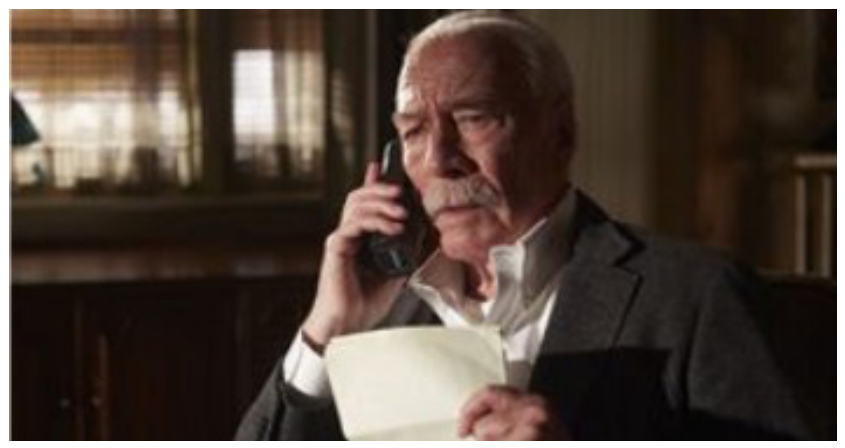

Max, que está impedido en una silla de ruedas, lanza así a Zev en una aparente misión de retaliación, que terminará siendo una búsqueda de su memoria e identidad. Zev está tomado por la palabra de Max, en tanto se presenta como aquel que es capaz de recordar por él, tanto el pasado como el deber ético de realizar una justicia reparadora: ubicar a Otto Wallisch, quien se oculta bajo la falsa identidad de Rudy Kurlander. Dado que hay sólo cuatro Kurlander que responden a la edad que debería tener el criminal, y dado que $Z$ ev es quien puede reconocerlo, deberá visitar a cada uno de ellos hasta dar con el verdadero Otto Wallisch y matarlo.

El film es el periplo de Zev en torno de esta búsqueda que -como Edipo- no es más que la búsqueda de sí mismo. Las etapas de este recorrido son a su vez significativas: en cada visita a un sospechoso se produce es un deslizamiento del objeto buscado. Wallisch es el nombre de un objeto aborrecible que se desliza, se hurta, hasta descubrirse como algo que siempre estuvo ya allí. Es el nombre de un objeto unbeimlich que se metonimiza, de Kurlander en Kurlander, hasta lograr nombrar su objeto.

Rudy Kurlander 1: Se llama así y fue soldado de Rommel. No estuvo en Auschwitz. Es el prototipo del alemán nacionalista que participó en la guerra. Su declaración es un cúmulo de inconsistencias: dice que en la guerra sirvió a su patria como soldado en el norte de África, y que es un alemán que está orgulloso de su servicio. Pero luego de la guerra este alemán orgulloso se fue a EEUU y se hizo ciudadano norteamericano. Afirma que sirvió a su país como soldado. O sea, no en calidad de nazi. Y que lo que hicieron los nazis con los judíos fue vergonzoso, pero que no supo sobre Auschwitz hasta después de la guerra. Luego agrega que los judíos le causaron problemas a su país -que es lo que los nazis sostenían-, que los judíos no le importaban y que pensó que los deportaban a campos de trabajo. "Fue una vergüenza... pero ese no fui yo". Que emplee el término "vergüenza" en vez de "crimen" resulta por lo menos sugestivo. La vergüenza es un sentimiento que surge como consecuencia de que un sujeto es descubierto ante la mirada del Otro. El afecto vergonzoso hace pie en el lugar del propio sujeto, no de la víctima, en tanto adviene como efecto de la caída de la imagen amable que el sujeto sostenía ante el Otro. Se trata de un sentimiento que viene en lugar de la culpa y hace obstáculo a la responsabilidad. Para Rudy, Auschwitz es vergonzoso, un exceso respecto de una política contra los judíos que tenía sus buenas razones. Los trabajos forzados en cambio no le hubieran dado vergüenza...

Rudy Kurlander 2: Estuvo en Auschwitz pero como víctima. No por su condición de judío, sino de homosexual. Postrado en la cama, delgado y moribundo, evoca a todas las víctimas de los campos. Antes de que Zev descubra esto, cree que es el genocida que busca y se da un malentendido: le explica que él estuvo en Auschwitz y que su familia fue asesinada. Rudy le dice que lo lamenta mucho, a lo que Zev le responde que lo que hizo es algo de lo que no puede pedir disculpas. Visto desde la mirada de las víctimas -y Zev cree que lo fue- el crimen de genocidio es imperdonable.

Rudy Kurlander 3: alemán nazi fallecido tres meses atrás. Su hijo, un oficial de policía, representa la transmisión de una herencia mortífera: como el padre, es un racista morbosamente fascinado por la historia del nazismo, al punto que llama Eva a su ovejero alemán, como la pareja de Hitler, y que al enterarse de que Zev estuvo en Auschwitz se entusiasma por querer escuchar los relatos del campo. Cuando descubre el tatuaje con los

\section{$\begin{array}{llll}\text { Kurlander } 1 & \text { Kurlander } 2 & \text { Kurlander } 3 & \text { Kurlander } 4\end{array}$}

\section{Soldado de Rommel}

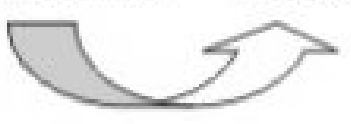

Otto Wallisch
Homosexual

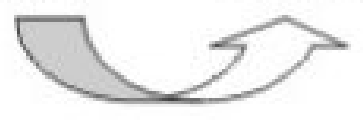

Otto Wallisch

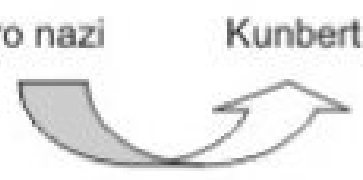

Otto Wallisch

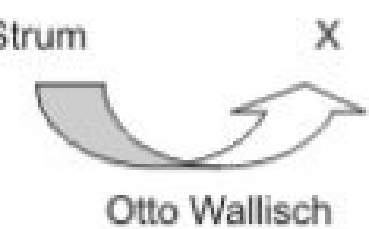

Otto Wallisch

UBA | UNC | UIO

ethicsandfilms.org

ISSN 2250-5660 print | ISSN 2250-5415 online 
números en el brazo de Zev, concluye que es un judío y, furioso, lo insulta y le lanza su perra para que lo ataque, en una repetición de tantas escenas de horror de los campos, como si no hubiera pasado la historia ni la justicia.

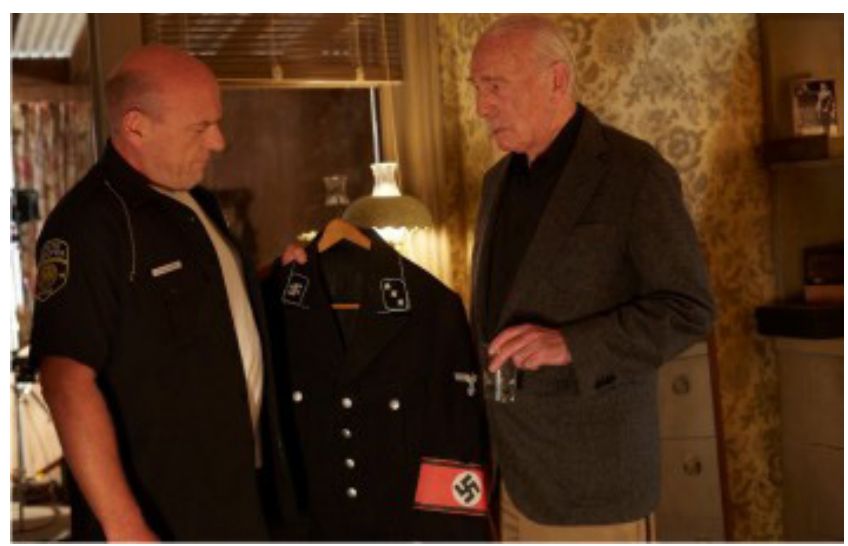

Rudy Kurlander 4: se trata de Kunibert Sturm, ex oficial de Auschwitz y compañero de Otto Wallisch, con quien al final de la guerra se hizo pasar por víctima judía para escapar de la justicia. Este encuentro final, con los hijos y nietos de ambos de involuntarios testigos, le permite a Zev encontrar finalmente el objeto de su búsqueda, que equivale a encontrarse con su pasado y su nombre propio. Si al final recuerda, es porque su otro semejante, verdadero doble especular de sí mismo, le devuelve su identidad como mensaje en forma invertida.

La trágica verdad se devela a partir del malentendido del nombre propio: Zev lo llama Otto al falso Kurlander, quien no acaba de comprender qué está pasando. Conminado bajo amenaza de muerte a confesar su secreto ante la propia familia y a decir su nombre, éste confiesa llamarse Kunibert Sturm. Zev le dice que no mienta, que se llama Otto Wallisch. Y entonces Sturm le grita que ese es su nombre, que ambos fueron compañeros en Auschwitz, y que se tatuaron mutuamente para hacerse pasar por víctimas. Cuando le recuerda que el nombre Zev fue elegido porque significa Lobo en hebreo, Otto lo mata.

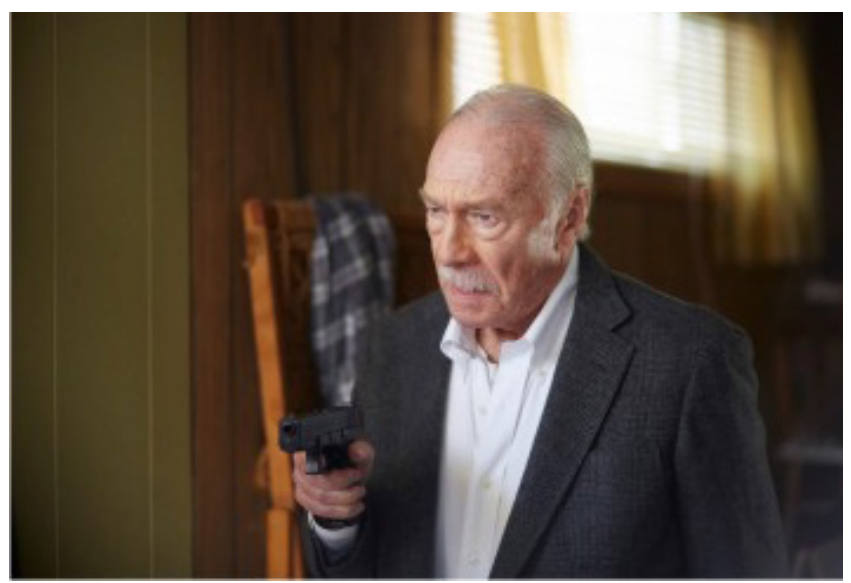

Una de las cuestiones del film es el problema entre memoria y recuerdo, la tensión entre registro de hechos pasados y la implicación del sujeto en los mismos, sea para evocarlos o para denegarlos. A lo largo del film, Egoyan nos va dando indicios de la verdad de Zev, sólo que lo suficientemente sutiles como para que los pasemos de largo: la incomodidad de Zev durante la ceremonia judía en el geriátrico, el significado de su nombre en hebreo ("lobo"), la consternación en la armería cuando buscan sus antecedentes, entre los cuales está el dato de si es un fugitivo de la justicia ("¿tengo aspecto de ser un fugitivo?” le dice al comerciante), la vehemente afirmación de que no mintió cuando el oficial neonazi lo acusa de haberlo engañado diciendo que era amigo de su padre, la sorprendente habilidad para manejar un arma de fuego en la casa del tercer Kurlander, y la ejecución al piano de una pieza de Wagner, el célebre compositor antisemita alemán. Hay en la conducta de Zev la puesta en juego de una memoria del hábito, un saber-hacer que queda en el recuerdo pero no requiere de la puesta en palabras (por ejemplo, andar en bicicleta o tocar un instrumento: uno se encuentra con que lo sabe, en un tipo de saber-hacer que no requiere pasar por la palabra, al punto de que si uno se lo pone a pensar, se obstaculiza la acción). Es este tipo de memoria encarnada la que opera como signo indicial de quien es Zev... pero para el espectador. No para Zev, es decir, para Wallich. Mientras su "cuerpo" recuerda hábitos como tocar Wagner en el piano o empuñar una Glock, esa memoria no pasa al campo significante. La memoria del hábito no lo abre a ninguna interrogación. En todo caso oficia como signos indiciales de que algo no cierra con Zev. Pero no funciona como vía hacia el recuerdo. Otto no se acuerda de sí mismo: está aferrado al sí mismo que Max le ha refrendado, y desde el lugar de víctima se dirige a vengar a "su familia". No sabe que así sigue el guión del Otro que oficia de memoria suplementaria.

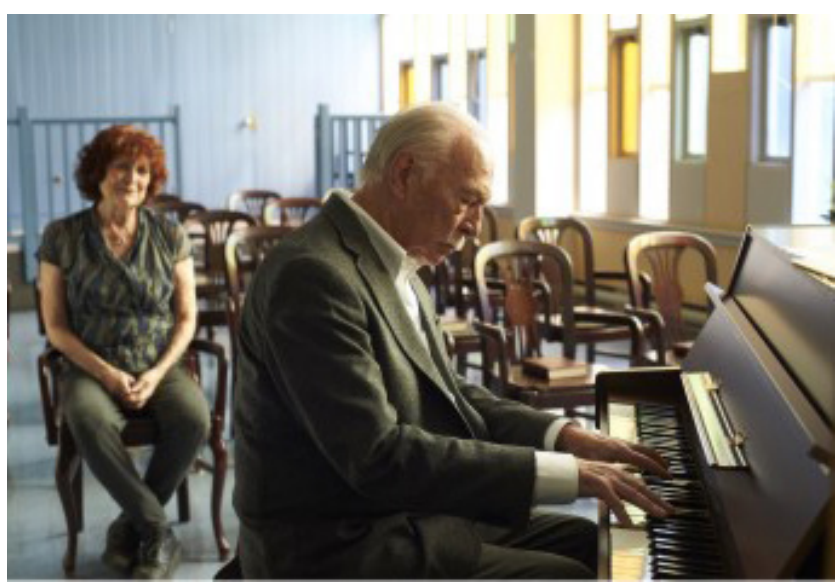


Zev sólo recuerda cuando Sturm le devuelve el nombre propio y le recuerda la traducción del nombre Zev: "Dijiste que éramos lobos" le grita, justo antes del disparo. La eficacia del nombre propio y el valor sintomático que porta la elección del nombre Zev tienen un efecto interpretativo e interpelativo: Rudy Kurlander es a $\mathrm{Ku}-$ nibert Sturm como Zev es a Otto Wallisch. Y "Zev" es significante del chiste siniestro de un nazi, que al mismo tiempo oculta y revela, que semidice la verdad de que un lobo se disfrazó de cordero para andar entre corderos.

\section{Rudy Kurlander $\underline{\text { Zev }}$ Strum Wallisch}

En el Seminario La ética del Psicoanálisis, Lacan afirma que "La ética consiste esencialmente (...) en un juicio sobre nuestra acción, haciendo la salvedad de que sólo tiene alcance en la medida en que la acción implicada en ella también entrañe o supuestamente entrañe un juicio, incluso implícito. La presencia del juicio de los dos lados es esencial a la estructura" (Lacan, 1992, p. 370) Lacan plantea un juicio implícito del lado del acto mismo -no hay acto que no entrañe un juicio que pone en juego una éticay un juicio ético por el acto realizado. Esta duplicación de los juicios no necesariamente coinciden: el juicio ético implícito en el asesinato masivo de judíos puede ser luego condenado como infame por el juicio que recae sobre dicho acto. Sólo cabe hablar de ética -es decir, de un juicio sobre el acto- cuando dicho acto acarrea la posición de un sujeto que ha puesto en juego implícitamente un juicio. El acto y su juicio ético implícito son luego juzgados, es decir, son pasibles de un juicio ético. A lo que Lacan le agrega la vara de medir el acto en relación al deseo que lo habita, para saber si el sujeto quiere o no lo que desea.
Una vez que Wallisch recuerda su acto genocida junto al juicio implícito del mismo, resta el juicio ético por dicha acción, ahora que recuerda y se recuerda. Hay apenas un segundo entre el rechazo de su pasado y el súbito cambio de Zev: mira casi con vergüenza a su hijo y sólo alcanza a decirle "yo recuerdo", antes de concluir con un tiro en la sien. Que esté identificado como víctima del holocausto, hace que su "yo recuerdo" le vuelva del Otro al modo de la torsión en una banda de Moebius: su yo es visto desde el otro que creía ser, desde la mirada de la víctima, y por eso se le vuelve monstruoso. Ese cambio de perspectiva impide que tenga la posición cínica en Sturm. Que además esté presente su hijo ante la revelación de su identidad para sí mismo y para los demás, impide cualquier salida de desresponsabilización.

Al final del film, el director le deja la última palabra a Max Rosembaun, para aclarar que el acto de Zev no es fruto de la demencia o de la instigación al suicidio motivado por las palabras que le escribió, sino una decisión, la conclusión a que llega como juicio ético por su acción. "Él sabía exactamente lo que estaba haciendo. El hombre que mató se llamaba Kunibert Sturm. Y el nombre de Zev era Otto Wallisch. Ellos fueron los hombres que asesinaron a mi familia" dice un Max conmovido. Cuando Zev adviene a la verdad de ser Otto Wallisch, finalmente despierta de su amnesia y ya no está más tomado por el guión del Otro. Ahora se trata de decidir qué hará con su pasado renegado y el peso de la culpa. Su nombre propio se ha vuelto el significante que le devuelve su posición de sujeto responsable. Responsable para decidir éticamente por sus actos. Sólo que se trata de actos imperdonables.

\footnotetext{
1 Arendt, H. (2007), Responsabilidad y juicio, Barcelona, Paidós.

2 Braunstein, N. (2012); La memoria del Uno y la memoria del Otro, México, Siglo XXI.

Grass, G. (2007); Pelando la cebolla, Barcelona, Alfaguara.
}

$4 \quad$ Es el punto débil del guión, dado que históricamente no hay registro de que haya ocurrido que unos nazis, para escapar de la justicia, se hayan mimetizado con ese otro aborrecible que representaba para ellos el judío. El racismo y el riesgo de ser reconocidos en la comunidad judía obraron de obstáculos insalvables para semejante estrategia. 